\title{
DESEMPENHO DO MÉTODO DE DISSIPAÇÃO TÉRMICA NA MEDIDA DO FLUXO DE SEIVA EM SERINGUEIRA
}

\author{
JUAN S. DELGADO-ROJAS ${ }^{1}$, CIRO A. RIGHI ${ }^{2}$, SHIGUEKAZU KARASAWA ${ }^{3}$, \\ LUIZ R. ANGELOCCI ${ }^{4}$, MARCOS S. BERNARDES ${ }^{5}$, MARCOS V. FOLEGATTI ${ }^{6}$
}

\begin{abstract}
RESUMO: A medida da transpiração de árvores no campo é de difícil consecução. Nas duas últimas décadas, tem-se dado ênfase à medida de fluxo de seiva no caule como indicador da transpiração, principalmente se a escala de tempo usada é igual ou menor que um dia. Para essas medidas, são usados métodos térmicos com fornecimento de calor ao caule. O método de dissipação térmica (MDT) é um deles e vem sendo bastante utilizado pelo seu princípio simples e pela boa sensibilidade às variações de fluxo de seiva. Entretanto, tem-se evidenciado a necessidade de cuidados no seu uso, sendo uma das causas de perda de precisão o efeito da carga radiante sobre a planta, geradora de gradiente térmico natural, que interfere nos resultados. Além disso, o desempenho do método em condições diferentes daquelas em que foi desenvolvido deve ser testado. Assim, o presente trabalho teve como objetivos analisar o desempenho do MDT em árvores de seringueira, considerando que essa espécie produz látex que poderia interferir sobre o bom funcionamento do sensor, e avaliar o efeito do gradiente térmico natural do caule sobre as estimativas. Os resultados demonstraram que essa técnica de medida pode ser utilizada nessa espécie e que, nas condições em que foram realizados os testes, não há interferência do gradiente térmico natural sobre as estimativas. Entretanto, para melhorar o grau de precisão, deve ser realizado melhor estudo de caraterização da área condutora da seiva em relação ao diâmetro do caule.
\end{abstract}

PALAVRAS-CHAVE: Hevea brasiliensis, fluxo de seiva, transpiração.

\section{PERFORMANCE OF A THERMAL DISSIPATION METHOD FOR SAP FLOW MEASUREMENT IN RUBBER TREE}

\begin{abstract}
The transpiration measurement of trees in field condition is very difficult. In the two last decades, some emphasis has been given in the study of stem sap flow as an indicator of plant transpiration. The methodology is particularly suitable for time scale less or equal than one day. One of the methods is the heat dissipation method (HDM), which has been used because of its simplicity and high sensitivity to the sap flow variations. However, the effect of the natural radiation, that generates a natural thermal gradient in stem, may lead to precision loss. Moreover, the performance of the method needs to be evaluated if the conditions are different from those for which it was developed. Thus, the present work aimed to analyze the performance of the HDM in rubber trees, considering that this specie produces latex that could affect the performance of the sensor, as well as to evaluate the effect of the natural thermal gradient of the stem on the estimated transpiration. The results had showed that HDM can be used with rubber trees and, in the conditions that tests were conducted, the natural thermal gradient does not effect the estimations. To improve the precision of the method, further studies, characterizing the tissue sap conductive area and the stem diameter should be made.
\end{abstract}

KEYWORDS: Hevea brasiliensis, sap flow, transpiration.

\footnotetext{
${ }^{1}$ Doutor em Irrigação e Drenagem, Pós-Doutorando, Departamento de Engenharia Rural, ESALQ/USP, Fone: (0XX19) 8112.2467, Bolsista CNPq, jsdrojas@esalq.usp.br

2 Doutor em Fitotecnia, ESALQ/USP, Bolsista da FAPESP.

${ }^{3}$ Doutorando, Departamento de Ciências Exatas, ESALQ/USP, Bolsista do CNPq.

${ }^{4}$ Prof. Dr., Departamento de Ciências Exatas, ESALQ/USP, Bolsista do CNPq.

${ }^{5}$ Prof. Dr., Departamento de Produção Vegetal, ESALQ/USP, Bolsista do CNPq.

${ }^{6}$ Prof. Dr., Departamento de Engenharia Rural, ESALQ/USP, Bolsista do CNPq.

Recebido pelo Conselho Editorial em: 16-2-2006
}

Aprovado pelo Conselho Editorial em: 24-10-2006

Eng. Agríc., Jaboticabal, v.26, n.3, p.722-729, set./dez. 2006 


\section{INTRODUÇÃO}

A determinação do fluxo de seiva é uma forma de quantificar a transpiração em plantas lenhosas, caso se trabalhe em escala diária e o déficit hídrico no solo não seja acentuado (VALANCOGNE \& NASR, 1993). Para fins de estudos fisiológicos, associados a outras observações, como o potencial da água na folha, à resistência estomática e às variações de diâmetro do caule, a determinação do fluxo de seiva constitui-se numa excelente ferramenta para analisar a reação da planta submetida a diferentes condições hídricas do solo e capacidade evaporativa do ar.

Dentre os métodos denominados de "térmicos" para a determinação do fluxo de seiva, o método de dissipação térmica (MDT) tem-se mostrado promissor, tendo já sido utilizado em grande número de espécies lenhosas, principalmente em espécies de plantas temperadas do Mediterrâneo (GRANIER, 1985, 1987; CABIBEL \& DO, 1991; KÖSTNER et al., 1998; LOUSTAU et al., 1998) e, nos últimos tempos, em espécies frutíferas, como videira (FERREIRA \& SILVESTRE, 2004) e pessegueiro (PAÇO \& FERREIRA, 2004). No Brasil, em árvores nativas, foi utilizado para medir a transpiração da Caferana, espécie típica da Amazônia (MOUTINHO, 2002) e para estudar a regulação estomática em condições de estresse hídrico, em diversas espécies do cerrado do planalto brasileiro (MEINZER et al., 1999; NAVES-BARBIERO et al., 2000). Em Piracicaba - SP, foi testado em limoeiro Tahiti (DELGADO-ROJAS, 2003) e em cafeeiro (DELGADO-ROJAS et al., 2004). Tais trabalhos evidenciaram a alta sensibilidade do método para detectar condições hídricas e intensidade de transpiração da planta, mas tem demonstrado, também, que há margem suficiente para melhorar sua precisão, pois há evidências de erros ou de subestimativas quando confrontado com medidas lisimétricas.

Uma das principais fontes de erros apontadas na literatura é aquela originária da perturbação térmica externa, que gera gradiente de temperatura ao longo do caule e acaba interferindo diretamente na medida do sensor e, conseqüentemente, na estimativa. CABIBEL \& DO (1991) denominam essa perturbação como "gradiente térmico externo". FERREIRA \& ZITSCHER (1996) a denominam de "gradiente térmico no tronco", e LUNDBLAD et al. (2001), de "gradiente térmico natural” (GTN). Com o intuito de padronizar a nomenclatura, no presente trabalho, será empregada essa última denominação. Outra fonte de erro importante é a definição da área condutora da seiva, ou seja, a área transversal ocupada pelo xilema, no ponto onde está inserido o sensor, que é efetiva em transportar a água. Essa área depende principalmente da espécie vegetal, da idade da árvore e do diâmetro do caule. A determinação dessa área é um dos problemas da técnica, pois exige o sacrifício da árvore, uma vez que ela deve ser cortada para realizar a medida correspondente. Uma informação que falta na literatura, é justamente a caracterização detalhada da relação entre o diâmetro do caule e a proporção da área condutora de seiva para cada espécie de interesse.

A seringueira, apesar de não ser normalmente irrigada, vem ganhando importância na região Sudeste do Brasil, pela sua potencialidade como espécie de duplo propósito, como reflorestamento e como geradora de renda. Nesse sentido, pretendeu-se observar a viabilidade da utilização de MDT nessa espécie, considerando que a seringueira exuda látex em qualquer ferimento do caule, o que poderia interferir nas medidas térmicas que envolvem esse método.

O presente trabalho teve como objetivos específicos avaliar o desempenho do MDT em seringueira (Hevea brasiliensis Müell. Arg.), dada a inexistência de literatura a respeito do emprego desse método em plantas produtoras de látex e analisar o efeito do GTN na estimativa do fluxo de seiva.

\section{MATERIAL E MÉTODOS}

O trabalho foi desenvolvido num seringal do setor experimental do Departamento de Produção Vegetal da ESALQ/USP, em Piracicaba - SP (latitude 22\%42’30'S, longitude 47 38'00' $\mathrm{W}$, altitude de $560 \mathrm{~m}$ ), entre agosto e dezembro de 2003. O pomar, formado pelo clone PB-235, foi implantado em 1991, com espaçamento de $8 \mathrm{~m}$ entre linhas e 2,5 m entre plantas. No experimento, foram utilizadas seis plantas, que foram numeradas de 1 a 6 , com diâmetro do caule com aproximadamente $18 \mathrm{~cm}$ na altura de inserção do sensor, a um metro do solo. 
Como parâmetro de caraterização da demanda evaporativa da atmosfera, foi utilizada a evapotranspiração de referência (ETo), calculada pelo método de Penman \& Monteith parametrizado pela FAO (SMITH et al., 1992). Os dados meteorológicos utilizados foram obtidos na estação agrometeorológica da instituição, localizada a aproximadamente $300 \mathrm{~m}$ do seringal.

Dada a dificuldade de medição da área foliar, as plantas foram caracterizadas visualmente pelo porte, sendo as plantas 3 e 6 as maiores, a 4 e 5 as menores e a 1 e 2 as intermediárias.

Devido à falta de método independente para aferir o método de dissipação térmica (MDT), uma das plantas (planta 6), que tinha uma bifurcação do tronco a uma altura de $3 \mathrm{~m}$, foi selecionada para se colocar um sensor nos dois ramos secundários, com o propósito de comparar a soma dos valores de fluxo de seiva (FS) de ambos com aqueles obtidos com o sensor do tronco principal.

Os sensores de fluxo de seiva foram confeccionados localmente, utilizando agulhas hipodérmicas e termopares de cobre e constantan (Tipo T), seguindo a descrição detalhada de GRANIER (1985). Com o intuito de quantificar o efeito do gradiente térmico natural (GTN), foi feita uma modificação no sensor, incluindo uma terceira sonda colocada em série, $5 \mathrm{~cm}$ abaixo das outras duas, na mesma linha vertical do caule. O esquema do sensor e das conexões elétricas está na Figura 1. Os sinais dos sensores foram registrados por um datalogger (Delta T, modelo DL2e), com leitura a cada 30 segundos e com registro dos valores médios a cada 10 minutos.

Para estimar o fluxo de seiva (FS, em $\mathrm{m}^{3} \mathrm{~s}^{-1}$ ), foi utilizada a seguinte equação, recomendada por GRANIER $(1985,1987)$ :

$$
\mathrm{FS}=118,9910^{-6}((\Delta \mathrm{TM}-\Delta \mathrm{T}) / \Delta \mathrm{T})^{1,231} \mathrm{AS}
$$

em que,

$\Delta \mathrm{TM}\left({ }^{\circ} \mathrm{C}\right)$ - diferença máxima de temperatura $\left({ }^{\circ} \mathrm{C}\right)$ entre os dois pontos de medida $(\mathrm{Tc}-\mathrm{Tb}$, conforme a Figura 1), que normalmente ocorre durante a madrugada;

$\Delta \mathrm{T}$ - diferença atual da temperatura $\left({ }^{\circ} \mathrm{C}\right)$ entre as duas sondas, e

$\mathrm{AS}$ - área condutora da seiva bruta $\left(\mathrm{m}^{2}\right)$, normalmente considerada equivalente à área ocupada pelo xilema. Como aproximação, foi considerada toda a área transversal do caule menos a área ocupada pela casca.

Para avaliar a interferência do gradiente térmico natural (GTN) do caule sobre as estimativas, foram analisados os valores térmicos obtidos por meio da medida diferencial entre as duas sondas não- aquecidas (Tb-Ta), conforme esquema da Figura $1 b$.

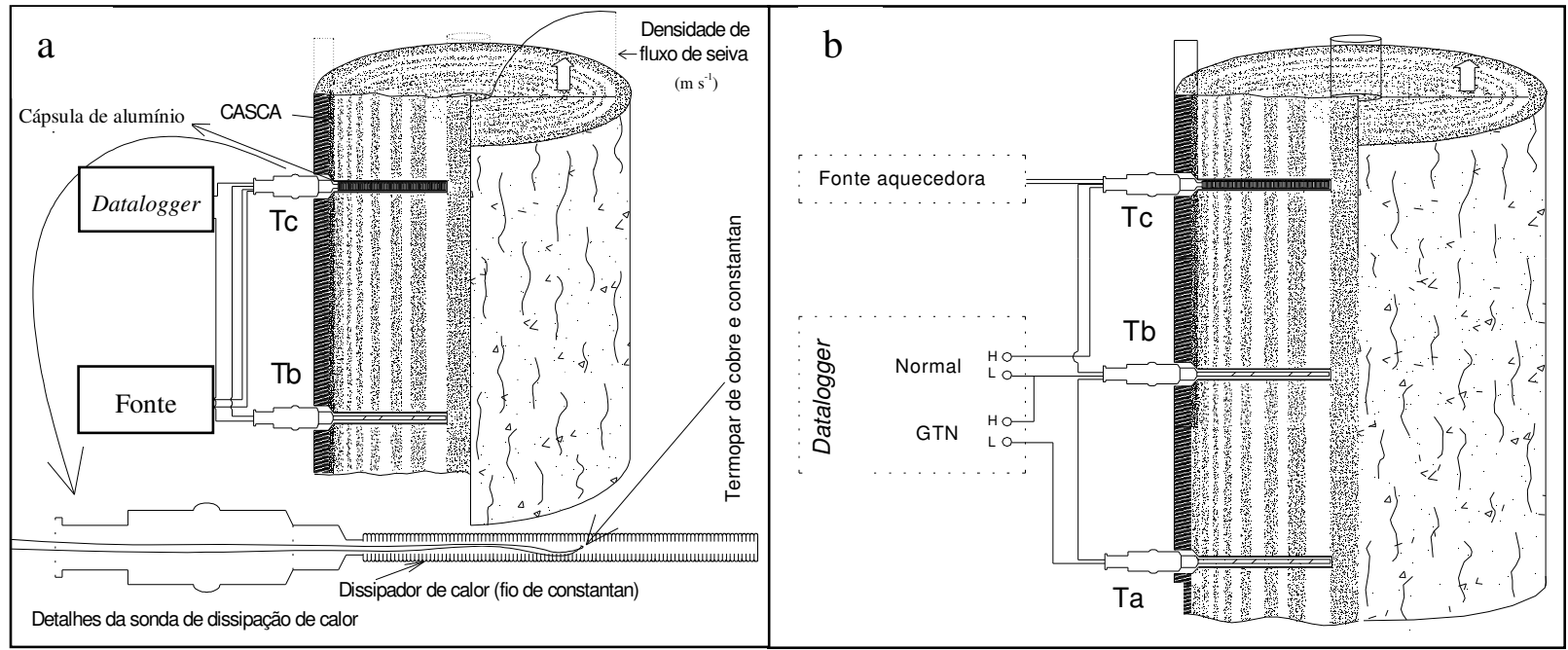

FIGURA 1. a) Sensor de fluxo de seiva, conforme GRANIER (1985), em que Tc é a sonda aquecida e Tb a não-aquecida. b) Sensor de fluxo de seiva modificado, que inclui uma sonda a mais (Ta) para detectar o GTN. Observam-se, também, detalhes da sonda aquecida e das conexões elétricas. 


\section{RESULTADOS E DISCUSSÃO}

Foi observado que, em geral, o GTN apresentou valores muito baixos que não interferiram sobre as medidas normais do sensor e, conseqüentemente, sobre as estimativas de fluxo de seiva. Na Figura 2, pode ser observado que esses valores chegaram a atingir apenas amplitude diária aproximada de $0,1^{\circ} \mathrm{C}$ por $5 \mathrm{~cm}$ de caule (eixo secundário), muito baixo, comparado à acusada pelas duas sondas superiores de Granier (entre a aquecida e a não-aquecida), que atingiram amplitudes acima de $2,4{ }^{\circ} \mathrm{C}$.

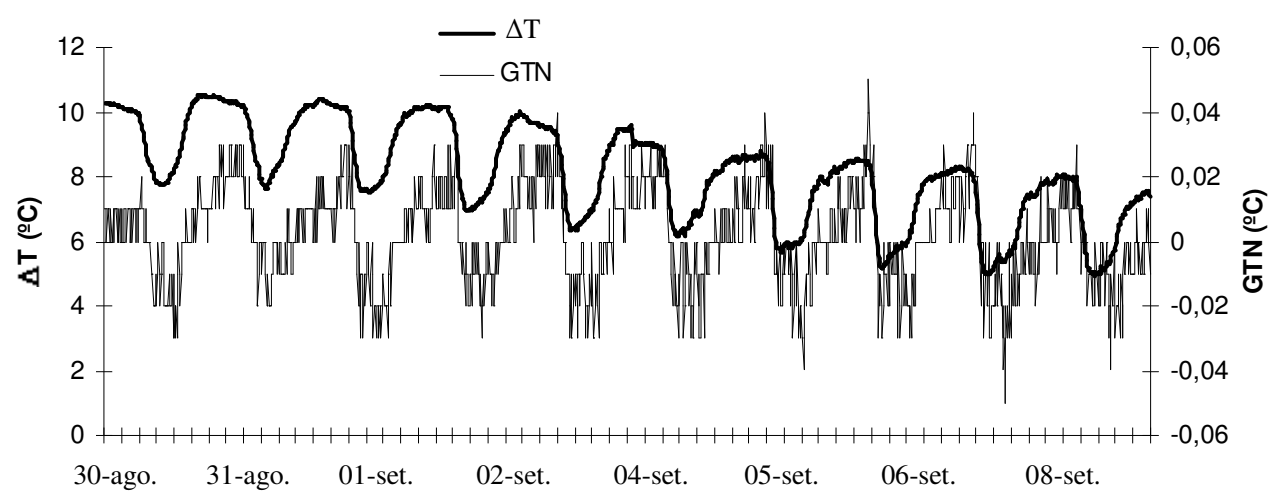

FIGURA 2. Evolução dos valores térmicos normais do sensor de Granier $(\Delta \mathrm{T})$ e dos valores do GTN medidos por meio da incorporação da terceira sonda. Dados obtidos durante 10 dias.

FERREIRA \& ZITSCHER (1996) e LUNDBLAD et al. (2001), realizando experiências com árvores adultas de grande porte, observaram que há interferências do GTN sobre as estimativas do fluxo de seiva. DELGADO-ROJAS (2003) e DELGADO-ROJAS et al. (2004) também observaram, em plantas de menor porte, como cafeeiro e limoeiro, que o mencionado gradiente apresenta acentuada interferência sobre as estimativas. Tudo indica que, quando as plantas têm baixa área basal (plantas jovens) ou baixa densidade por área, pode haver maior incidência da carga térmica do ambiente sobre as mesmas, sofrendo com maior facilidade a interferência do GTN. Quanto menores as plantas, o efeito pode ser mais acentuado, principalmente pelo reduzido diâmetro do caule, que é afetado mais facilmente, tanto pela energia transportada advectivamente como a que foi transformada no local.

No caso do presente experimento, a alta densidade de plantio, que condicionou praticamente sombra permanente no interior de seringal e, conseqüentemente, pequena carga radiante sobre o caule, o porte das plantas, que já era relativamente grande, e o sentido azimutal de inserção do sensor (lado sul do caule), padronizado para obter o menor risco possível de ser atingido pela radiação direta do sol, além da estrutura refletiva instalada sobre os sensores, fizeram com que o mencionado gradiente não tivesse interferido sobre as estimativas do fluxo de seiva.

Quanto à evolução do fluxo de seiva, foi observado que esse teve comportamento coerente, considerando que, nos primeiros dois meses (agosto e setembro), houve acentuado déficit hídrico no solo, pois a chuva acumulada foi de apenas $8,9 \mathrm{~mm}$ em junho, 16,4 $\mathrm{mm}$ em julho, 17,6 $\mathrm{mm}$ em agosto e $12 \mathrm{~mm}$ em setembro, o que refletiu diretamente sobre a transpiração diária que não acompanhou a tendência normal da demanda evaporativa do ar. Em agosto e setembro, o fluxo de seiva ficou em nível bastante menor do que de outubro a novembro, ou seja, não foi proporcional em magnitude à variação de ETo ao longo dos meses (Figura 3).

Por outro lado, como observado por outros autores, verificou-se a sensibilidade desse método em acompanhar a demanda evaporativa do ar. Na Figura 4, observou-se que, quando as plantas estiveram submetidas a diferentes demandas evaporativas do ar, caracterizada pela ETo, a tendência do fluxo de seiva acompanhou essa mudança brusca, de um dia para o outro. 


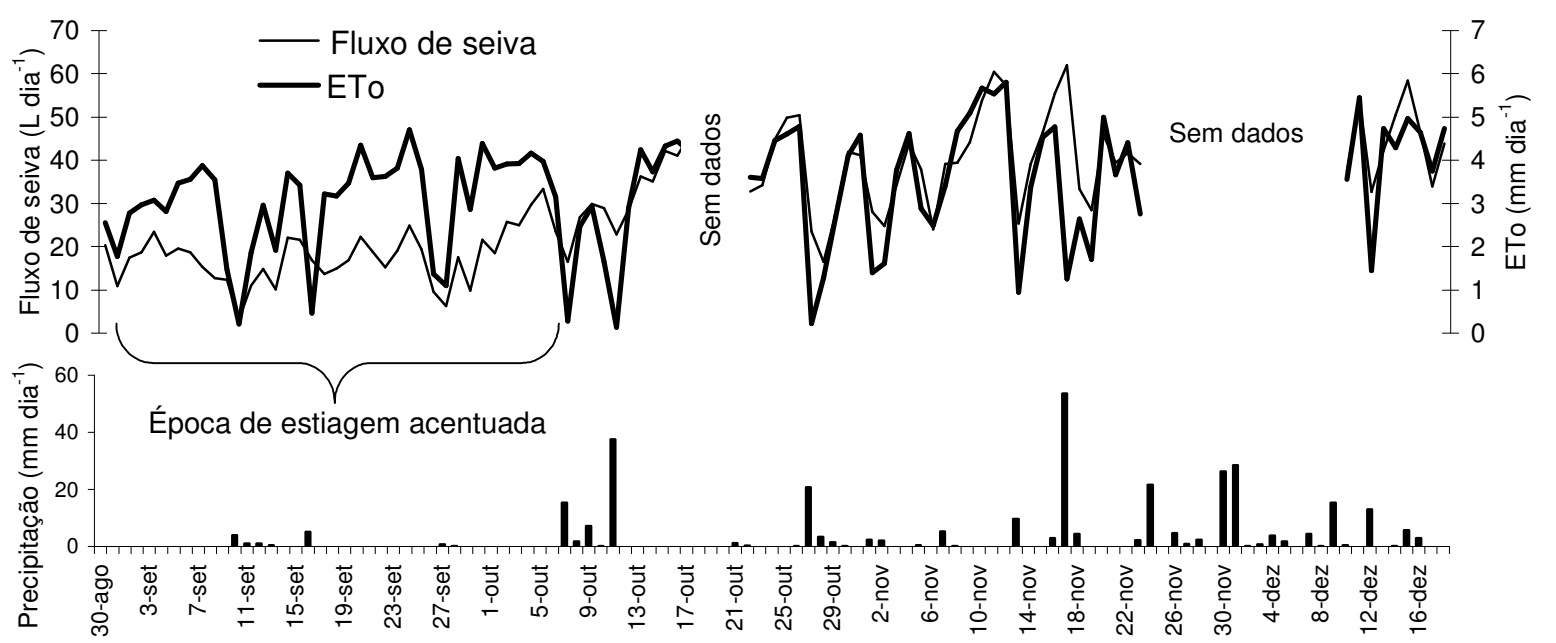

FIGURA 3. Evapotranspiração de referência (ETo) e transpiração diária estimada em base ao fluxo de seiva calculado pelo método de Granier, observadas entre os dias 30 de agosto e 18 de dezembro de 2003, medidas em planta de seringueira de 12 anos de idade.

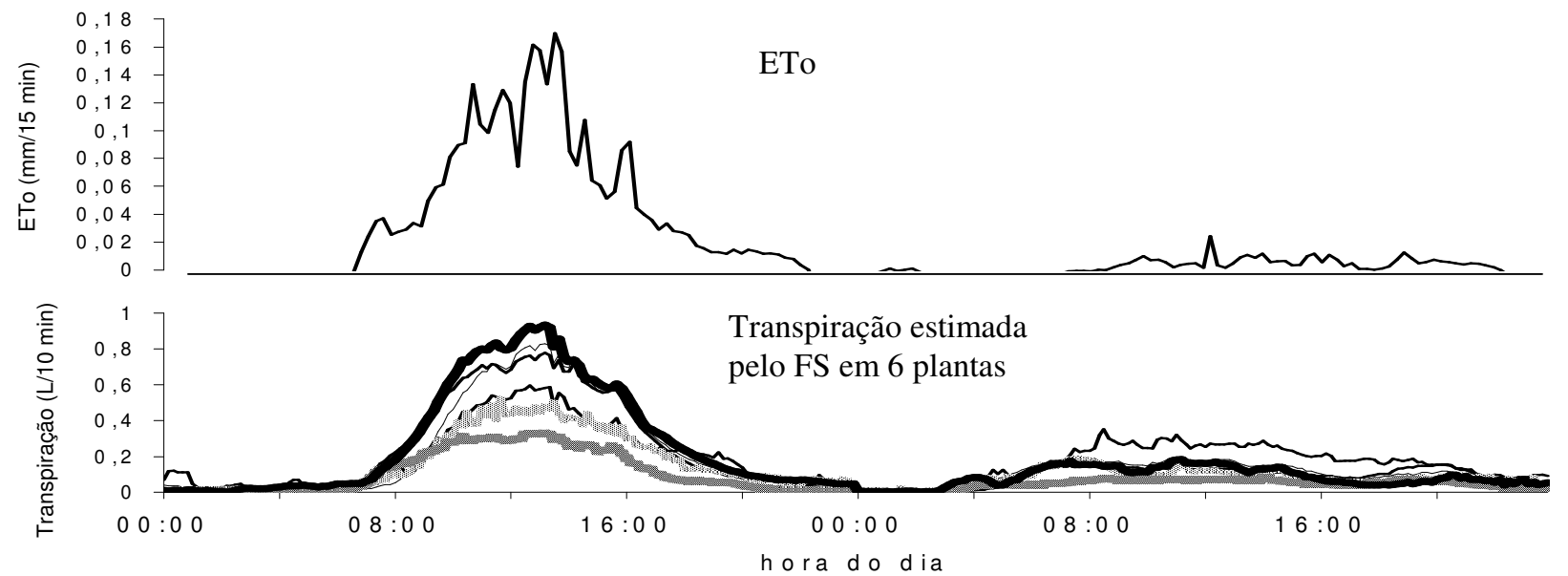

FIGURA 4. Evolução da evapotranspiração de referência (ETo) e da transpiração, estimada por meio do fluxo de seiva (FS), durante dois dias consecutivos, com diferentes demandas evaporativas do ar. Medidas feitas em seis plantas de seringueira, nos dias 10 e 11 de outubro de 2003.

Ao ser analisada a soma dos valores da transpiração estimada (Tabela 1), foi verificado que houve coerência conforme o tamanho das árvores, pois as plantas 3 e 6 tinham os maiores valores de área foliar, enquanto as plantas 4 e 5, com menores valores de área foliar, apresentaram os menores valores de fluxo de seiva.

Analisando a transpiração total acumulada de 2.096,6 L para a planta 6, obtida com a soma dos valores estimados nos dois caules secundários, durante 45 dias, e a obtida no caule principal da mesma planta no período, que somou 2.041,6 L, observou-se diferença de apenas $55 \mathrm{~L}$, ou seja, inferior a 3\%. Na Figura 5, observaram-se alguns pontos dispersos, que correspondem aos primeiros dias do mês de outubro, quando ocorreu déficit hídrico, o que permite antecipar que, nessas condições, o método pode perder precisão, talvez pela distribuição desuniforme da taxa de fluxo de seiva na área transversal do caule. Isso talvez seja por causa do alto grau de heterogeneidade na distribuição da água no solo, tal como presumem alguns autores (CABIBEL \& DO, 1991). 
TABELA 1. Transpiração $\left(\mathrm{L} \mathrm{dia}^{-1}\right)$ de seis plantas de seringueira, incluindo dois ramos da planta número 6, ramos a e b. estimada a partir do fluxo de seiva medido por meio do método de Granier.

\begin{tabular}{|c|c|c|c|c|c|c|c|c|}
\hline Data & Planta 1 & Planta 2 & Planta 3 & Planta 4 & Planta 5 & Planta 6 & $\begin{array}{c}\text { Planta } 6 \\
\text { ramo a }\end{array}$ & $\begin{array}{c}\text { Planta } 6 \\
\text { ramo b }\end{array}$ \\
\hline $1 \%$ out. & 18,53 & 39,06 & 37,13 & 27,75 & 22,25 & 53,64 & 12,01 & 52,87 \\
\hline 2/out. & 25,81 & 40,20 & 48,64 & 27,79 & 23,62 & 51,99 & 11,49 & 45,07 \\
\hline 3/out. & 25,02 & 45,53 & 50,83 & 27,26 & 25,44 & 52,28 & 11,02 & 38,55 \\
\hline 4/out. & 29,75 & 45,49 & 52,73 & 27,98 & 24,43 & 54,72 & 11,09 & 38,56 \\
\hline 5/out. & 33,41 & 47,95 & 50,92 & 27,70 & 27,33 & 56,16 & 10,92 & 54,45 \\
\hline 6/out. & 23,48 & 33,86 & 44,53 & 23,67 & 17,07 & 40,79 & 9,18 & 27,70 \\
\hline 7/out. & 16,52 & 10,79 & 11,85 & 7,19 & 6,44 & 12,61 & 3,39 & 10,27 \\
\hline 8/out. & 26,83 & 25,73 & 25,38 & 15,90 & 13,30 & 24,75 & 6,59 & 23,51 \\
\hline 9/out. & 29,84 & 36,88 & 40,87 & 28,27 & 25,52 & 56,18 & 10,41 & 55,13 \\
\hline 10/out. & 28,87 & 36,09 & 35,09 & 24,20 & 16,25 & 41,41 & 8,04 & 22,46 \\
\hline 11/out. & 22,88 & 13,07 & 14,80 & 11,45 & 6,62 & 12,31 & 8,07 & 12,89 \\
\hline 12/out. & 28,53 & 34,94 & 31,76 & 26,35 & 16,03 & 38,73 & 9,79 & 34,06 \\
\hline 13/out. & 36,19 & 43,52 & 42,77 & 32,04 & 20,89 & 46,11 & 10,39 & 38,13 \\
\hline 14/out. & 35,13 & 40,68 & 42,82 & 27,38 & 18,53 & 43,72 & 8,88 & 30,91 \\
\hline 15/out. & 42,17 & 42,47 & 50,08 & 32,18 & 19,30 & 46,98 & 10,74 & 37,20 \\
\hline 16/out. & 41,12 & 46,62 & 61,03 & 36,84 & 20,79 & 51,58 & 11,46 & 47,70 \\
\hline 17/out. & 45,65 & 48,15 & 54,50 & 40,43 & 24,53 & 53,44 & 11,12 & 34,96 \\
\hline 18/out. & $X$ & X & X & X & X & 53,39 & 13,11 & 50,20 \\
\hline 19/out. & $X$ & X & X & X & $X$ & 53,13 & 12,96 & 43,25 \\
\hline 20/out. & $X$ & X & X & X & X & 43,64 & 10,67 & 38,25 \\
\hline 21/out. & $X$ & X & X & X & $X$ & 30,51 & 8,25 & 24,83 \\
\hline 22/out. & 32,82 & 30,15 & 34,48 & 25,58 & 16,71 & 40,76 & 10,44 & 35,01 \\
\hline 23/out. & 34,24 & 37,10 & 32,19 & 27,76 & 17,72 & 40,69 & 9,23 & 27,44 \\
\hline 24/out. & 44,80 & 39,61 & 37,78 & 34,19 & 19,00 & 51,08 & 10,46 & 40,23 \\
\hline 25/out. & 49,85 & 40,88 & 39,53 & 38,78 & 22,67 & 59,54 & 12,05 & 41,22 \\
\hline 26/out. & 50,40 & 45,69 & 44,59 & 48,39 & 21,94 & 55,74 & 11,26 & 38,50 \\
\hline 27/out. & 23,51 & 11,45 & 14,49 & 8,16 & 7,25 & 15,87 & 7,17 & 19,17 \\
\hline 28/out. & 16,55 & 18,68 & 16,42 & 14,92 & 11,27 & 22,80 & 5,64 & 16,18 \\
\hline 29/out. & 27,67 & 23,79 & 30,24 & 17,92 & 16,93 & 35,10 & 7,53 & 27,42 \\
\hline 30/out. & 41,90 & 36,03 & 34,27 & 21,25 & 21,23 & 58,32 & 10,54 & 41,43 \\
\hline 31/out. & 41,19 & 34,84 & 35,67 & 22,05 & 23,06 & 50,03 & 10,84 & 41,47 \\
\hline 1\%/nov. & 28,12 & 28,06 & 21,78 & 14,65 & 15,30 & 34,26 & 7,95 & 27,59 \\
\hline 2/nov. & 24,81 & 27,04 & 16,11 & 18,20 & 18,05 & 33,53 & 8,55 & 28,07 \\
\hline 3/nov. & 34,26 & 38,04 & 36,11 & 26,85 & 17,62 & 44,37 & 10,69 & 31,91 \\
\hline 4/nov. & 43,88 & 42,16 & 40,97 & 29,72 & 22,17 & 52,59 & 13,90 & 39,44 \\
\hline 5/nov. & 37,95 & 35,09 & 29,64 & 27,94 & 19,15 & 41,73 & 10,50 & 42,32 \\
\hline 6/nov. & 23,99 & 36,77 & 24,20 & 24,78 & 15,05 & 37,09 & 8,75 & 33,03 \\
\hline 7/nov. & 39,09 & 36,19 & 46,81 & 33,10 & 21,18 & 47,68 & 11,42 & 44,56 \\
\hline 8/nov. & 39,49 & 37,96 & 42,45 & 32,51 & 21,79 & 50,83 & 10,95 & 40,41 \\
\hline 9/nov. & 44,22 & 44,35 & 42,31 & 33,56 & 25,45 & 60,55 & 12,94 & 49,02 \\
\hline 10/nov. & 53,81 & 48,01 & 52,33 & 35,01 & 27,63 & 66,24 & 13,36 & 54,68 \\
\hline 11/nov. & 60,50 & 53,61 & 52,73 & 36,46 & 29,52 & 75,58 & 14,61 & 54,47 \\
\hline 12/nov. & 57,39 & 43,96 & 52,03 & 31,05 & 25,49 & 71,77 & 13,65 & 47,58 \\
\hline 13/nov. & 25,37 & 35,75 & 45,33 & 15,07 & 10,81 & 23,22 & 6,30 & 17,36 \\
\hline 14/nov. & 39,15 & 42,30 & 50,21 & 27,39 & 19,90 & 54,18 & 12,47 & 36,25 \\
\hline Total * & $1.424,69$ & $1.498,54$ & $1.568,42$ & $1.089,71$ & 795,21 & $1.860,96$ & 415,79 & $1.479,19$ \\
\hline Total ** & & & & & 875,41 & $2.041,62$ & 460,77 & $1.635,73$ \\
\hline
\end{tabular}




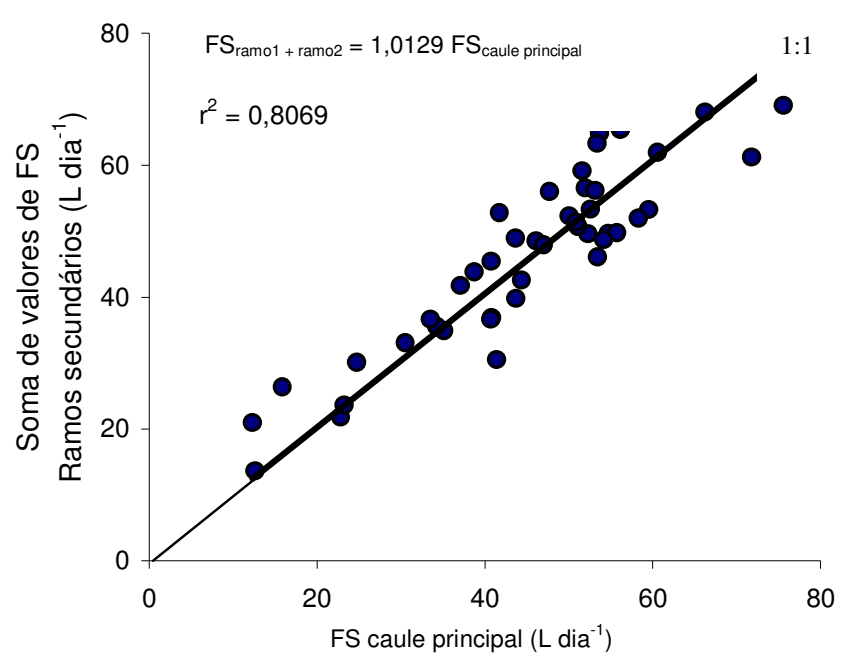

FIGURA 5. Ajustes entre os valores de fluxo de seiva medidos no caule principal de uma planta de seringueira (planta 6 da Tabela 1) e em dois ramos secundários da mesma planta. Medidas diárias realizadas entre os dias $1^{0}$ de outubro e 14 de novembro de 2003.

Vale esclarecer que o trabalho realizado, apesar de denotar coerências nos resultados, teve duas principais limitações: a falta da determinação da área condutora da seiva e a falta de uma equação de calibração apropriada; pois a equação de Granier, aplicada no trabalho, foi gerada para espécies de plantas temperadas. Nesse sentido, é difícil dizer se houve subestimativa ou superestimativa de fluxo de seiva. No entanto, pela Figura 4, é demonstrado que, solucionando essas duas limitações, o método pode ser utilizado confiavelmente.

Nesse sentido, a falta de comparação com uma medida independente não permite concluir o grau de exatidão dessa técnica. Um aspecto fundamental a ser estudado é quanto à área efetiva de fluxo do xilema, pois o erro nela cometido é repassado diretamente para a medida de FS [eq.(1)] Entretanto, a resposta à demanda atmosférica e a concordância dos valores independentes dos sensores na árvore 6 indicam que o método pode ser usado em seringueira. É importante ressaltar que, após um tempo de permanência no caule (aproximadamente dois anos), formou-se uma crosta em volta das sondas inseridas, o que deixa claro que as mesmas não podem permanecer por longo tempo numa região do caule, devendo ser deslocadas para outra posição, porém mantendo-se a mesma orientação azimutal.

\section{CONCLUSÕES}

Nas condições em que foi realizado o experimento (alta densidade de plantação), não houve interferência do gradiente térmico natural (GTN) sobre as estimativas de fluxo de seiva (FS). Portanto, não há necessidade de compensar o erro ocasionado pelo gradiente térmico; entretanto, recomenda-se não prescindir do sensor de Granier modificado (de três sondas), pois ele pode explicar erros pontuais e dar maior segurança sobre o comportamento das medidas térmicas.

O método de Granier (sonda de dissipação térmica - SDT) mostrou-se potencialmente utilizável em plantas de seringueira, mas recomenda-se que uma calibração independente seja executada para garantir sua precisão, incluindo a determinação da área efetiva do xilema.

\section{REFERÊNCIAS}

CABIBEL, B.; DO, F. Mesures thermiques des flux de sève dans les troncs et les racines et fonctionnement hydrique des arbres: I. Analyse théorique des erreurs sur la mesure des flux et validation des mesures en présence de gradients thermiques extérieurs. Agronomie, Paris, v.11, p.669-78. 1991. 
DELGADO-ROJAS, J.S. Avaliação do uso do fluxo de seiva e da variação do diâmetro do caule e de ramos na determinação das condições hídricas de citros, como base para o manejo de irrigação. 2003. 110 f. Tese (Doutorado em Irrigação e Drenagem) - Escola Superior de Agricultura "Luiz de Queiroz", Universidade de São Paulo, Piracicaba, 2003.

DELGADO-ROJAS, J.S.; KARASAWA, S.; ANGELOCCI, L.R. Determinación de la transpiración del café (Coffea arabica L.) através del método de sonda de disipación térmica. In: REUNIÓN ARGENTINA, 5., LATINOAMERICANA DE AGROMETEOROLOGIA, 9., 2004, La Plata. Anais...Buenos Aires: Asociación Argentina de Agrometeorologia, 2004. 1 CD-ROM.

FERREIRA, M. I.; ZITSCHER, H. Measurements performed with Granier method in short trunks near the soil. In: WORKSHOP ON MEASURING SAP FLOW IN INTACT PLANT, 3., 1996, Barcelona. Anais... p.1-3.

FERREIRA, M.I.; SILVESTRE, J.C. Medição da transpiração em cobertos descontínuos: vinha em diferentes declives, na região do oeste. In: CONGRESSO DA ÁGUA, 7., 2004, Lisboa. Anais...Lisboa: Associação Portuguesa dos Recursos Hídricos, 2004. p. 1-11.

GRANIER, A. Une nouvelle méthode pour la mesure du flux de sève brute dans le tronc des arbres. Annales des Sciences Forestières, Nancy, v.42, n.2, p.193-200, 1985.

GRANIER, A. Mesure du flux de sève brute dans le tronc du douglas par une nouvelle méthode thermique. Annales des Sciences Forestierès, Nancy, v.44, n.1, p.1-14, 1987.

KÖSTNER, B.; GRANIER, A.; CERMÁK, J. Sapflow measurements in forest stands: methods and uncertainties. Annales des Sciences Forestierès, Paris, v.55, p.13-27, 1998.

LOUSTAU, D.; DOMEC, J.C.; BOSC, A. Interpreting the variations in xylem sap flux density within the trunk of maritime pine (Pinus pinaster Ait.): application of a model for calculating water flows at tree and stand levels. Annales des Sciences Forestierès, Paris, v.55, p.29-40, 1998.

LUNDBLAD, M.; LAGERGREN, F.; LINDROTH, A. Evaluation of heat balance and heat dissipation methods for sapflow measurements in pine and spruce. Annals of Forest Science, Bethesda, v.58, n.6, p.625-38, 2001.

MEINZER, F.C.; GOLDSTEIN, G.; FRANCO, A.C.; BUSTAMANTE, M.; IGLER, E.; JACKSON, P.; CALDAS, L.; RUNDEL, P.W. Atmospheric and hydraulic limitations on transpiration in Brazilian cerrado woody species. Functional Ecology, London, v.13, n.2, p.273-82, 1999.

MOUTINHO, P.R. de S. Efeito da seca prolongada na Amazônia: quando a floresta torna-se inflamável? 2002. Disponível em: <http://lba.cptec.inpe.br/lba/port/documentos/projetos/LC14.pdf>. Acesso em: 30 abr. 2005.

NAVES-BARBIERO, C.C.; FRANCO, A.C.; BUCCI, S.J.; GOLDSTEIN, G. Fluxo de seiva e condutância estomática de duas espécies lenhosas sempre-verdes no campo sujo e cerradão. Revista Brasileira de Fisiologia Vegetal, Campinas, v.12, n.2, p.119-34, 2000.

PAÇO, T.A.; FERREIRA, M.I. Medição da evapotranspiração em cobertos descontínuos. Necessidades de rega em pomar de pessegueiro. In: CONGRESSO DA ÁGUA, 7., 2004, Lisboa. Anais...Lisboa: Associação Portuguesa dos Recursos Hídricos, 2004. p.1-13.

SMITH, M.; ALLEN, R.; MONTEITH, J.L.; PERRIER, A.; PEREIRA, L.; SEGEREN, A. Report on the expert consultation on revision of FAO methodologies for crop water requirements. Rome: FAO, 1992. $44 \mathrm{p}$.

VALANCOGNE, C.; NASR, Z. A heat balance method for measuring sap flow in small tress. In: BORGHETTI, M.; GRACE, J.; RASCHI, A. Water transport in plants under climatic stress. Cambridge: Cambridge University Press, 1993. p.166-73. 